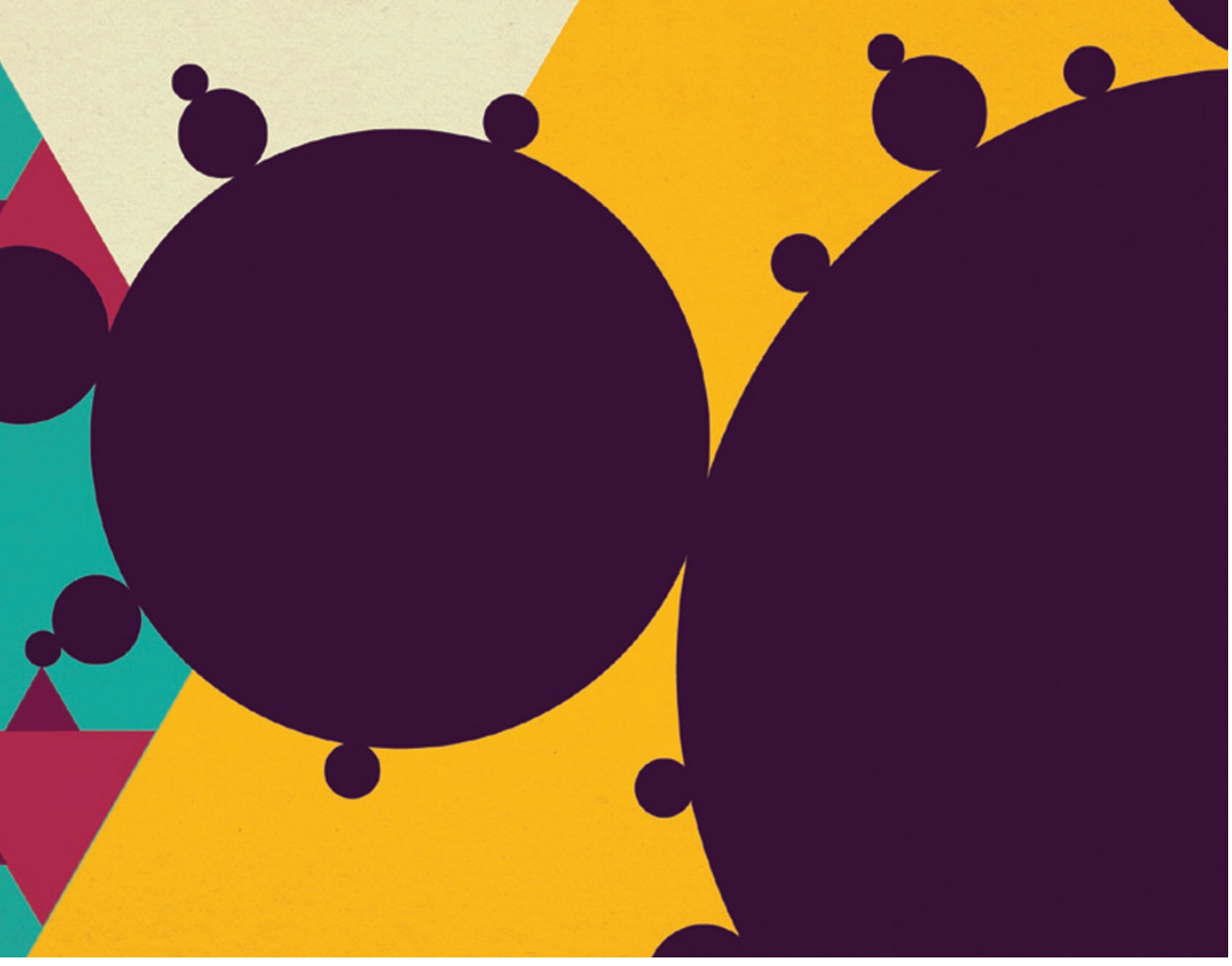

MATHEMATICS

\title{
A fractal life
}

\section{Mark Buchanan enjoys the quirky memoir of a mathematical rebel - the late Benoît Mandelbrot.}

A t the start of The Fractalist is a photograph dated June 1930. In a Jewish family's apartment in Warsaw, four Polish mathematicians are hosting a meal for an honoured guest - French mathematician Jacques Hadamard. Somewhere in the same house, although not pictured, would have been a six-year-old named Benoit. The family's surname was Mandelbrot.

A hugely productive theorist of geometry and roughness, and the "father of fractals", Benoit Mandelbrot died aged 85 on 14 October 2010. The Fractalist is his posthumously published autobiography, polished with help from his former assistant and colleagues.

A collection of poignant vignettes, the memoir paints Mandelbrot as an intellectual individualist who created his own field. $\mathrm{He}$ was reputedly a prickly character, self-important and quick to take offence. Traces of his strong opinions come through, but they are overwhelmed by warm and delightful reminiscences of family and colleagues.

Mandelbrot explains that in that 1930 photo are several of the most important people in his life. Key among them is his mathematician uncle, Szolem. The first in the family to attend university, Szolem Mandelbrot had travelled to Paris to study mathematics under Hadamard, and went on to hold the same chair at the Collège de France as Henri Poincaré. He was Mandelbrot's informal mentor, and linked the family to international science.

In 1936, as European civilization began to dissolve, Mandelbrot's "lucid and decisive" parents took the family to Paris to join Szolem. Benoît recalls learning about the history and architecture of the city during long walks. When the war started, the family fled occupied Paris for rural Tulle in the unoccupied Limousin region.

Danger was never far away, and in 1943, the family went into hiding and the parents and children split up. Posing as apprentice tool-makers, Benoît and his cousin Leon
The Fractalist: Memoir of a Scientific Maverick BENOIT MANDELBROT Pantheon: 2012. 352 pp. $\$ 30$

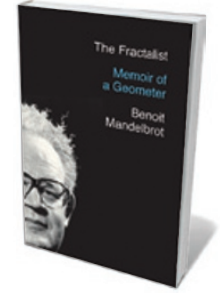
aroused suspicion and were arrested by the police, who were seeking the culprits of a bombing. Days of anguish followed before a helpful official intervened on their behalf.

Through such kindnesses, and the determination of his parents, Mandelbrot survived the war. Back in Paris, his mathematical skill gained him entrance to the prestigious École Polytechnique. This would have guaranteed him a comfortable career in France, but Mandelbrot never settled for the safe option.

In one vignette, Mandelbrot recalls a "lifealtering verbal lashing from Szolem”. It was 1952 and Mandelbrot, aged 28, was back in Paris after studying fluid dynamics and aircraft design at the California Institute of Technology in Pasadena. He hadn't chosen a topic for his $\mathrm{PhD}$, and Szolem berated him for excessive book learning and preparation to be a "well-trained monkey".

Szolem suggested pursuing quadratic dynamics, the sometimes complex behaviour of mathematical functions when iterated - plug in a number, take the result and plug that back in again, endlessly. Mandelbrot looked into the topic, then dropped it. But the lashing had an effect. Soon, Szolem pointed Mandelbrot to the linguist George Zipf, who had found a scaling law in the relative frequency of word use that seemed to be universal across languages. "Silly stuff only you can like" was Szolem's view. Benoît, to the alarm of his professors, chose it as his thesis topic and so set a course to revolutionize science.

Mandelbrot's insight that the apparently random might harbour hidden order broadened over his postdoc positions at the Massachusetts Institute of Technology (MIT) in Cambridge; Princeton University in New

\section{NEW IN PAPERBACK \\ Highlights from this season's releases}

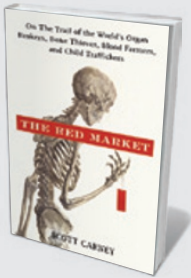

The Red Market: On the Trail of the World's Organ Brokers, Bone Thieves, Blood Farmers, and Child Traffickers Scott M. Carney (William Morrow, 2012; \$14.99)

From illegal adoptions to a bag of tibias used to make flutes on the IndoBhutanese border, Scott Carney explores the illegal trade in human bodies and body parts. His investigation into this shadowy realm exposes a system that exploits donors, benefits middlemen and puts a price on our very existence. (See Laura Spinney's review: Nature 474, 156-158; 2011.) 
Jersey; and the University of Geneva in Switzerland. In 1958, he began a 35-year career at the IBM Research Center in Yorktown Heights, New York.

His work on market fluctuations in the 1960s could have revolutionized financial economics if the field's equilibriumfocused ideology hadn't pushed it aside for 30 years. Perceiving parallels in everything from fractured surfaces to stock-market movements, Mandelbrot coined the term fractals and did more than anyone to make it possible to talk about natural roughness and disorder in a precise, scientific way.

In 1979, he returned to Szolem's suggestion of quadratic dynamics. Within a year, his explorations of functional iterations led him to discover the Mandelbrot set - an astonishing pattern of infinite richness produced by simple rules. This launched a whole branch of mathematics.

Much of what makes The Fractalist fun to read is Mandelbrot's scattered recollection of encounters with luminaries. At MIT he discussed linguistics with the young Noam Chomsky and argued with anthropologist Margaret Mead. Robert Oppenheimer liked his ideas, and Mandelbrot worked with the famed psychologist Jean Piaget in Geneva and computing pioneer John von Neumann at Princeton.

Mandelbrot recalls how after one of his lectures, a famous mathematician objected, saying he had made "absolutely no sense at all”. Oppenheimer and von Neumann sprang into action, explaining points that even Mandelbrot hadn't noticed. The meeting, he remembers, "went from abysmally low to unforgettably high". His appreciation of friends, music and quirky mathematics colours every page of The Fractalist. Mandelbrot's odd habits explain why he was so original: he avoided work involving direct competition with others, and naturally worked in the gaps between fields, in blind spots.

"A youthful decision set me on a maverick's lonely ride," he writes. "Its consequences took a long time to develop."

Mark Buchanan is a physicist and writer based in France. His latest book is The Social Atom.

e-mail:buchanan.mark@gmail.com

\title{
Stemming the red tide
}

\author{
Lab luminaries jostle with consumptive cultural icons in a \\ vivid history of tuberculosis, finds Stefan H. E. Kaufmann.
}

$\mathrm{T}$ Uuberculosis has killed more people than all wars combined, and was a leading cause of death in many Western megacities as recently as the 1950s. Historically, tuberculosis (TB) was hothoused in overcrowded European and US cities: at the start of the twentieth century in New York and Berlin, it killed $40 \%$ of people aged $25-40$. Yet TB was in decline until the late twentieth century, when the HIV/AIDS epidemic in subSaharan Africa triggered a resurgence. Now, it is the number one cause of death among people with HIV, and the incidence of multidrug-resistant strains is rising.

But the story goes beyond the medical. TB's long history, wide spread and lethality irrevocably link it to social and cultural history, as Helen Bynum reveals in her gripping history of the disease and its impacts, Spitting Blood.

Bynum kicks off with the case of George Orwell, which encapsulates the progression of TB and its impact on culture. In 1949, when Orwell published Nineteen Eighty-Four, he was in the late stages of the disease, which arguably influenced his novel's dystopian tone; he died a year later. Bynum goes on to expertly turn the many facets of TB to the light, from biology to medicine and socioeconomics. She ends with a brief account of why it has not been eradicated.

TB is caused by Mycobacterium tuberculosis, a bacterium that probably evolved from an environmental microbe to a human pathogen. The signs of 'consumption' or phthisis - pulmonary TB, triggered by aerosol infection of the lung - are coughing and spitting of blood. Before the nineteenth century, another common form was scrofulosis, in which the lymph nodes became pus-filled and ulcerated. It usually arises from ingesting bacteria, so the increasing eradication of bovine TB and the sterilization of milk have radically reduced its incidence. Pott's disease, a third, rare form, affects the bones.
Phthisis and scrofulosis were known in antiquity. But it was not until the late Renaissance that anatomists came to recognize TB lesions, and spotted similarities between the manifestations of the disease.

TB began to gain cultural cachet as artists succumbed. The death at 25 of English Romantic poet John Keats (a trained surgeon) did much to glamorize the disease. In Rome in 1820, Keats "vomited near two cupfuls of blood"; he died a few months later. Anne Brontë and, possibly, her sister Emily succumbed at 29 and 30. Consumption became linked to the punishment and redemption of a bohemian life, as with the courtesan Violetta in Giuseppe Verdi's 1853 opera La Traviata.

Meanwhile, as Bynum shows, the medical disease began to emerge, and "consumption became tuberculosis". Louis Pasteur provided the first evidence that microbes caused certain diseases. Robert Koch showed that TB was infectious, and demonstrated that a single pathogen was responsible for its different forms. At the time, clinicians tried to treat the disease using the 'pneumothorax' method, collapsing the lung by inserting needles into the pleural cavity, in the hope that pressure on the lung would lead to a cure. But

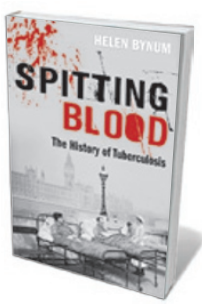

Spitting Blood: The History of Tuberculosis HELEN BYNUM Oxford Univ. Press: 2012. 352 pp. £16.99, $\$ 34.95$ the unveiling of TB as a bacteriological disease paved the way for effective drugs, diagnostics and a vaccine.

In the second half of the nineteenth century, efforts to control public spitting began. Dispensaries were set up, then sanatoriums for the rich, the first in Germany in the 1860s. Working class sanatoriums emerged courtesy

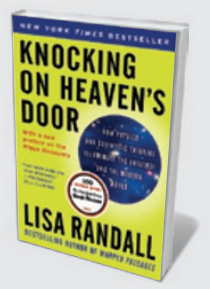

Knocking on Heaven's Door

Lisa Randall (Ecco, 2012; \$16.99)

What can CERN's Large Hadron Collider (LHC)

reveal about the make-up of the Universe? Particle physicist Lisa Randall explains, alternating details of the LHC's inner workings with more general musings on the philosophy of science. (See Joseph Silk's review: Nature 477, 30-31; 2011.)

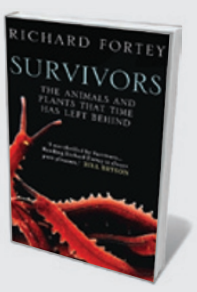

Survivors: The Animals and Plants that Time Has Left Behind Richard Fortey (Harper, 2012; £9.99) Palaeontologist Richard Fortey narrates the history of life by looking not to the long-extinct, but to organisms that have survived, almost unchanged, for millions of years. These survivors, he says, speak to us of pivotal evolutionary events. 
of national-insurance programmes and philanthropy. People with joint and bone TB, often children, underwent orthopaedic treatments, such as wearing shells and jackets that left just face and ears exposed.

In 1921, as Bynum reveals, Albert Calmette and Camille Guérin devised the first breakthrough: the vaccine bacille Calmette-Guérin (BCG). Twenty years later, Albert Schatz and Selman Waksman discovered the second: the TB drug streptomycin. Intensive research spawned others, and the 1950s saw the first broadscale fight against $\mathrm{TB}$, with mass $\mathrm{X}$-ray screening and drug therapy. But although national TB-control programmes sprang up, interrupted treatments and poor patient compliance led to drug resistance, notably in regions of conflict and asylum camps. From the beginning, resistance against single drugs was noted, and clinical trials spearheaded by the UK Medical Research Council revealed that multidrug therapy was essential for preventing the development of drug-resistant strains.

A rigorous multi-drug treatment programme led by the World Health Organization (WHO) effectively defeated non-resistant TB, but about 50 million people currently harbour multi-drug-resistant tubercle bacilli. Of these, nearly half a million develop the disease each year. With around 15 million people co-infected with HIV and tubercle bacilli, and nearly 1 million active TB cases a year among people with HIV, we are seeing a perfect storm. If Bynum's book has a weakness, it is that it lacks an outlook on how the WHO's goal to eliminate TB by 2050 could be achieved.

Spitting Blood provides impressive insight into TB as a medical and social disease. Meanwhile, photographer James Nachtwey's gallery of people with drugresistant TB (www.xdrtb.org) complements this work on a disease that is still very much with us. In 2009, London alone harboured nearly 3,500 TB cases: an almost $50 \%$ increase over the preceding decade.

Stefan H. E. Kaufmann is director of the department of immunology at the Max Planck Institute for Infection Biology in Berlin.

e-mail:kaufmann@mpiib-berlin.mpg.de

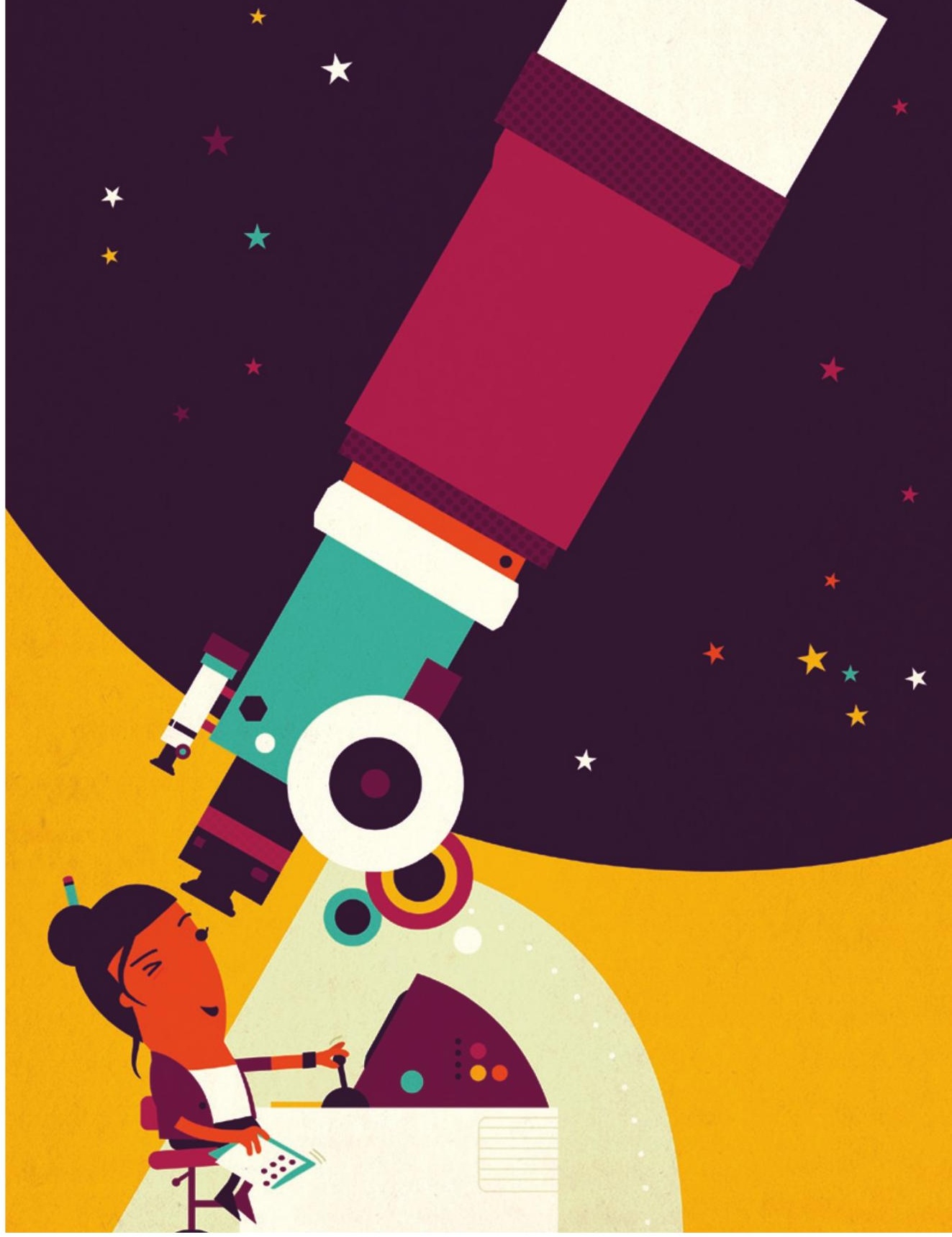

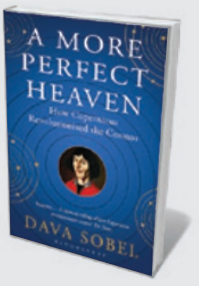

A More Perfect Heaven: How Copernicus

Revolutionised the Cosmos

Dava Sobel (Bloomsbury, 2012; £8.99)

Mixing drama with history, Dava Sobel offers a biography of Copernicus with a twist, working in a two-act play in which a student convinces him to publish his revolutionary work. (See Owen Gingerich's review: Nature 477, 276-277; 2011.)

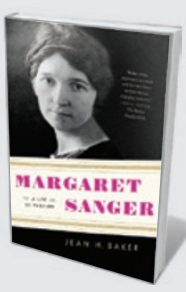

Margaret Sanger: A Life of Passion

Jean H. Baker (Hill and Wang, 2012; \$17.00)

Margaret Sanger emerges as a daring and

determined character in historian Jean Baker's vivid life. Sanger's fervent belief that women should be able to limit the size of their families led to the development of the contraceptive pill. (See W. F. Bynum's review: Nature 478, 318; 2011.) 
$\mathrm{P}$ eople have pondered the existence of Earth-like worlds beyond our Solar System for millennia. In 1995, the first exoplanet was spotted, orbiting a Sun-like star. Fewer than two decades later, hundreds of planets and thousands of candidates are known. Yet the sheer variety of exoplanet masses, sizes and orbits indicates that close copies of the Solar System are rare.

In Mirror Earth, science writer Michael Lemonick relates astronomers' abiding interest in sister worlds, from ancient Greece where Aristotle surmised that there is only one world, Earth - to today, and beyond. Spotting a small, light and faint planet near its massive, bright host star is difficult and requires abstruse techniques. Lemonick sets out these methods - radial velocity, transits, microlensing, direct imaging, astrometry and pulsar timing - with impressive clarity.

NASA's Kepler space telescope is rightly a focus of the book. The Kepler mission's goal is to establish how common Earth-size planets in Earth-like orbits about Sun-like stars are. But, as Lemonick is careful to spell out, these will not necessarily be Earth 'twins' planets with water oceans, continents and thin atmospheres conducive to life.

Knowing a planet's size doesn't tell us whether it is habitable. Venus, for example, is about the same size as Earth but not at all Earth-like. A thick carbon dioxide atmosphere causes greenhouse heating of the surface to temperatures exceeding 700 kelvin, hot enough to melt lead.

The Kepler telescope, launched in March 2009 and trailing Earth as the planet orbits the Sun, is making astonishing discoveries. One is that 'mini-Neptunes' - planets a few times Earth's diameter and a little smaller than Neptune - are many times more common than larger 'Jupiters', planets about 11 times the size of Earth. There are hints that smaller planets may be even more numerous. This tantalizing finding could imply that rocky planets (thought to reach no more than 1.75 times Earth's size) outnumber their gas-rich cousins.

Kepler has also vastly increased our knowledge of the variety of planetary systems. These include single planets orbiting two suns and dozens of multiple-planet systems, some in surprisingly compact orbits. The book covers the zoo of planetary types thought to exist, as well as theories of planet formation, conditions for habitability and the origin of life.

Lemonick describes Kepler's rocky road from conception to launch, including how its technical feasibility was repeatedly challenged, leading to the proposal being rejected by NASA several times. And he discusses the implication of the recent realization that most Sun-like stars are more variable than our Sun. That means Kepler must scour them for twice as long to pick out the signature dimming of

\section{KNOWING A PLANET'S SIZE DOESN'T TELL US WHETHER IT IS HABITABLE.}

passing planets, doubling the time it will take to reach the census goal.

Finding exoplanets is an art as well as a science, and Lemonick gives examples to demonstrate how hard it can be to tease a weak signal out of data. "It's my Rembrandt," declared exoplanet hunter Paul Butler of his computer code - six years in the making - that cracked the puzzle of how to measure the precise motion of a star caused by an orbiting planet. Controversy invariably follows about which detections are robust,

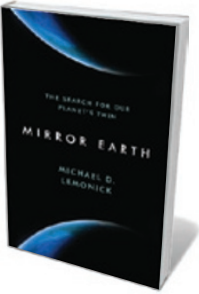

Mirror Earth: The Search for Our Planet's Twin MICHAEL D. LEMONICK Walker: 2012. 304 pp. $\$ 26, £ 19.99$ and Lemonick captures some of those lively exchanges with quotes and stories.

Lemonick provides a brutally honest character exposition of wellknown exoplaneteers. He details Geoff Marcy's feelings of being, in Marcy's words, "an impostor" early in his career owing to a severe lack of confidence that plagues many young scientists, and Debra Fischer's unusual route into astrophysics via nursing.

One intriguing thread in the book is the tension between scientists and journalists. Exoplanet discoveries are ripe for misinterpretation and exaggeration. The media and the public want an exciting story even when there is none, and it is easy for a scientist to get caught up in the hype. Lemonick describes how one astronomer felt he was induced by a journalist to say that "the chances for life" were "100 percent" on a new planet, the very existence of which is now challenged.

Mirror Earth captures the excitement of planet hunting and the ups and downs of discovery. Yet today, the quest for an Earth twin remains just out of reach. To identify a truly Earth-like world will require a more sophisticated space telescope than Kepler, to look for water and signs of life. Lemonick speculates on how that might happen. It may take decades to see how the story really unfolds. Stay tuned.

Sara Seager is a professor of planetary science and a professor of physics at the Massachusetts Institute of Technology in Cambridge.

e-mail: seager@mit.edu

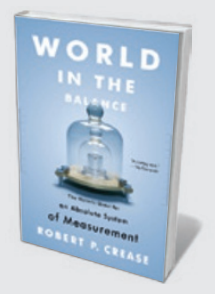

World in the Balance: The Historic Quest for an Absolute System of Measurement Robert P. Crease (W. W. Norton, 2012; \$17.95) From weighing out food to telling the time, we have long sought to measure experience. Robert Crease traces the origins of such rules, which now seem "part of the contour of things". (See Andrew Robinson's review: Nature 478, 32-33; 2011.)

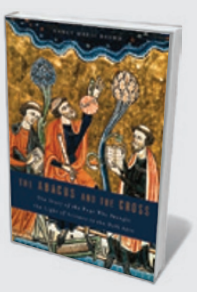

The Abacus and the Cross

Nancy Marie Brown (Basic Books, 2012; \$16.99) The idea that anti-scientific superstition defined the Middle Ages is challenged by science writer Nancy Marie Brown in this life of 'Scientist Pope' Gerbert of Aurillac. Gerbert devised early forms of the computer and the planetarium, and his teaching helped spread science through Europe. 


\section{A fringe too far}

\section{David Morrison finds contemporary echoes in a history of 'science wars', from Velikovsky to Lysenko and beyond.}

$\mathrm{F}$ rom creationism and climate-change denial to cold fusion, pseudoscience pervades the media, often drowning out real science. Michael Gordin's scholarly and highly readable The Pseudoscience Wars uses Immanuel Velikovsky's 'cosmic catastrophe' theory - once a hugely influential recasting of ancient history - as the organizing principle for a discussion of modern pseudoscience and "science wars". The book also covers Lysenkoism and young-Earth geology in depth.

Gordin, a science historian, asserts that scientists apply the label of pseudoscience which he defines as "doctrines that are nonscience but pretend to be, or aspire to be, or are simply mistaken for scientific" - only to ideas whose public appeal makes them seem threatening. His goal is to examine how scientists try to deal with the issue of 'outsiders' and understand their thinking, and what light the Velikovsky phenomenon sheds on that.

For much of the past half-century, Velikovsky's big idea both enjoyed public popularity and drew the opprobrium of scientists. A Russian immigrant to the United States, Velikovsky was a psychiatrist by training, yet thought of himself as a historian who used the insights of psychoanalysis to interpret the myths of early civilizations. He collected and correlated myths from the first and second millennia BC, many dealing with catastrophes such as the Egyptian plagues described in the Bible's Old Testament. Eventually, he began to propose cosmic events that could explain things that happened in the myths.

By the late 1940s, Velikovsky had convinced himself that Earth had nearly collided with Venus and Mars between 2000 and 800 BC. This grand synthesis was published in 1950 as Worlds in Collision, followed by several further books and dozens of articles. In spite of scathing criticism from other scientists, he

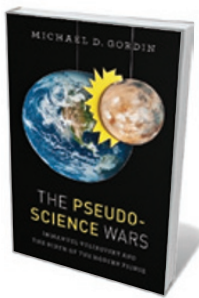

The

Pseudoscience Wars: Immanuel Velikovsky and the Birth of the Modern Fringe MICHAEL D. GORDIN University of Chicago Press: 2012. 304 pp. $£ 18.50, \$ 29$ never wavered from his conviction: a few weeks before his death in 1979, he said: "No one has disproved Worlds in Collision."

The book became a best-seller. But Velikovsky wanted to be recognized as a bona fide scholar. He was stung by harsh reviews, including pressure from prominent scientists that resulted in the book being dropped by Macmillan (which publishes this journal), then the main publisher of science textbooks in the United States, and transferred to the trade publisher Doubleday.

Velikovsky sought scientific legitimacy by courting individual scientists, especially Albert Einstein, who, like Velikovsky, lived in Princeton, New Jersey. Gordin discusses these efforts and the mainly hostile reactions to them. Scientists recognized that Velikovsky's planetary collisions, and his suggestion that electromagnetism rather than gravitation dominated planetary motions, were (in Einstein's term) "crazy". Velikovsky was simply not speaking the same language as the scientific community, yet his books were received uncritically by many of the public.

If the story had ended there, he would quickly have retreated into oblivion. But in the 1970s, Velikovsky became a symbol of the US counterculture. His reissued books hit the best-seller lists again; students invited him to speak on college campuses, and he acquired a group of enthusiastic disciples.

This assault from a crank baffled the scientific community. Gordin adds context

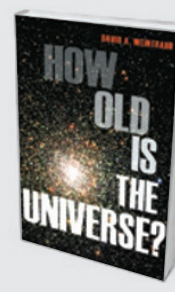

How Old Is the Universe?

David A. Weintraub (Princeton Univ. Press, 2012; \$22.95)

Astronomers do not believe the Universe is 13.7 billion years old, writes David Weintraub; they know it. But how? Weintraub chronicles centuries of scientists' painstaking work gauging the ages of planets and stars to arrive at the answer.

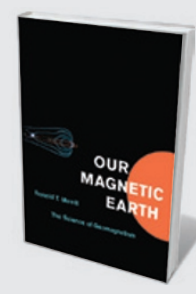

Our Magnetic Earth: The Science of Geomagnetism Ronald T. Merrill (Univ. Chicago Press, 2012; \$17.00)

Earth scientist Ronald Merrill draws together topics relating to geomagnetism, from mammals using the magnetic field for sensing to what magnetized rocks reveal about Earth's history. 
with the tale of the agronomist and pseudoscientist Trofim Lysenko, whose theory of heredity, supported by Joseph Stalin, came close to destroying the science of genetics in the Soviet Union. One reason scientists so strongly opposed Velikovsky was the recent, chilling memory of Lysenkoism.

There are fascinating and alarming parallels between these outsider narratives and Christian creationists' use of pseudoscientific arguments to lend legitimacy to their cause. Henry Morris and John Whitcomb's 1961 publication The Genesis Flood (Presbyterian and Reformed Publishing) became the foundation of the 'creation science' movement. Like Velikovsky, these authors postulated a catastrophic history of Earth, reinterpreting all geology in terms of a single universal flood, as described in chapters 6-11 of Genesis. They based their conclusions solely on a literal interpretation of scripture, and rejected Velikovsky's naturalist explanations.

Pseudoscience that has the support of organized religion or economic interests tends to survive much longer than the work of a lone eccentric such as Velikovsky. In his final pages, Gordin touches on a new phase of pseudoscience, practised by a few rogue scientists themselves. Climate-change denialism is the prime example, in which a handful of researchers, allied with an effective public-relations machine, are publicly challenging the scientific consensus that global warming is real and is attributable mainly to human consumption of fossil fuels. Deniers' questioning of the climate data and their attacks on the integrity and motivations of the scientists involved was exemplified by the e-mail-hacking 'climategate' scandal of 2009. This is perhaps the greatest threat from pseudoscience today.

Velikovsky and Lysenko may be largely forgotten, but other forms of pseudoscience are flourishing - among both the public and many politicians. Gordin's historical analysis of pseudoscience remains disturbingly relevant.

David Morrison is the director of the Carl Sagan Center for Study of Life in the Universe in Mountain View, California. e-mail:dmorrison@seti.org

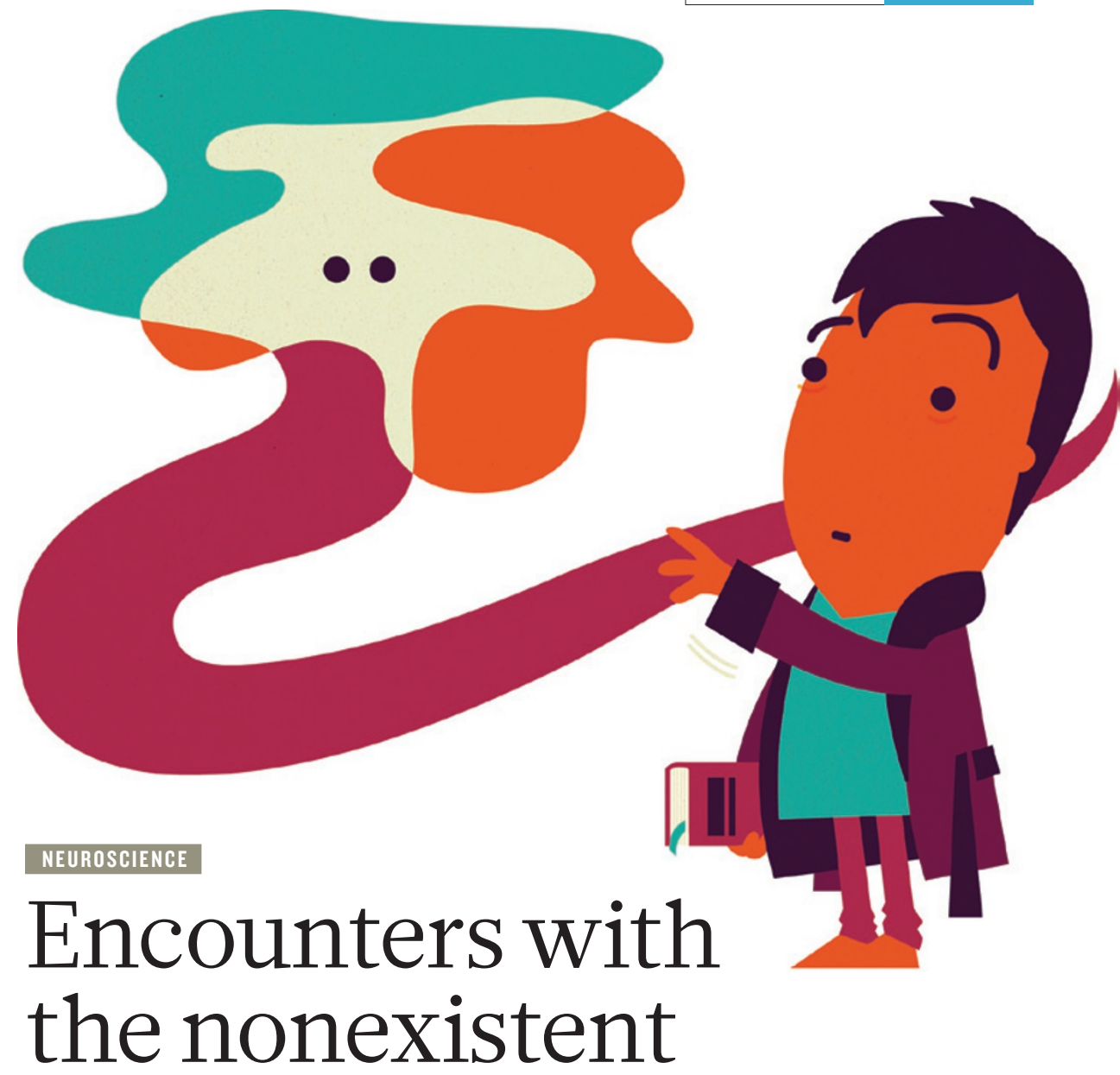

Dominic ffytche contemplates Oliver Sacks' journey through the past and future science of hallucinations.

$\mathrm{O}$ liver Sacks' Hallucinations opens with something of an apology. The neurologist explains that his book will not focus on cutting-edge brainimaging studies of what happens during a hallucination or what predisposes individuals to having them; rather, it will concentrate on first-person accounts, with the aim of understanding what it is like to hallucinate. It is as if Sacks worries that such an approach is insufficiently scientific, in an era of functional and structural neuroimaging.

Such concerns are unfounded. Imaging studies have made significant contributions to the field, but it is still Sacks' clinical territory — where the listening, archiving

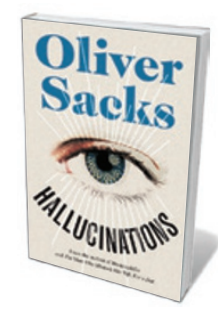

Hallucinations

OLIVER SACKS

Picador/Knopf:

2012. 336/352 pp.

$£ 18.99 / \$ 26.95$ and recognition of repeated patterns of symptoms takes place - that sets the research agenda.

By analogy to eighteenth-century catalogues of flora and fauna from different corners of the world, Sacks structures his book as a 'natural history' of hallucinations. Chapter by chapter, he describes the various clinical and physiological settings in which people have hallucinations. They might

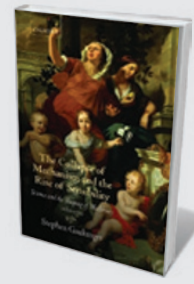

The Collapse of Mechanism and the

Rise of Sensibility

Stephen Gaukroger (Oxford Univ. Press, 2012;

£25)

Historian of philosophy Stephen Gaukroger charts how a sensory view of nature coincided with the novel's rise in 1680-1760. (See George Rousseau's review: Nature 470, 462-463; 2011.)

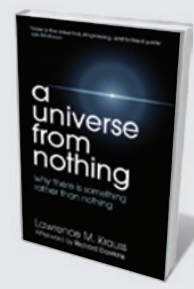

A Universe from Nothing: Why There Is

Something Rather than Nothing

Lawrence M. Krauss (Simon \& Schuster, 2012; $£ 8.99$ )

The current thinking on multiverses, dark energy and what is meant by 'nothing' is unpicked by theoretical physicist Lawrence Krauss. (See Caleb Scharf's review: Nature 481, 440; 2012.) 
> see indecipherable writing, or miniature costumed figures (visual hallucinations); smell dill pickles (olfactory hallucinations); or hear incessant renditions of the song White Christmas (musical auditory hallucinations).

Using descriptions from his patients, correspondents and published accounts, Sacks covers areas as diverse as eye disease, stroke, drugs (in poignant revelations from his own past) and bereavement, as well as bizarre perceptual experiences that defy simple classification. Such classificatory dilemmas include the case of Sarah, who saw herself from the ceiling of an operating theatre (in an 'out of body' experience); and Ellen, whose brother's profile remained fixed in her vision for days (visual perseveration). What all such experiences share is that the perceived object either isn't there or differs in some way from how others would perceive it.

In the neurology clinic, hallucinations tend to be visual; in the psychiatric clinic, the overwhelming majority are auditory - specifically, voices. Sacks writes from a neurologist's perspective, so his catalogue of visual phenomena and other neurological symptoms is comprehensive and scholarly. Hallucinated voices and other manifestations of schizophrenia and bipolar disorder he mentions only in passing. They require, he suggests, a book of their own.

Hallucinations gives Sacks the opportunity to explore an area new to him: the paranormal. Before the twentieth century, hallucinations were often seen as belonging to the domain of spiritualism, ghost hunting, telepathy, crystal gazing and divination. The most detailed survey of hallucinations ever undertaken remains the International Census of Waking Hallucinations in the Sane, conducted in the 1890s for the Society for Psychical Research in London, to uncover evidence for communication from the dead.

Chapter titles such as 'Phantoms, Shadows, and Sensory Ghosts' and 'The Haunted Mind' remind us of these metaphysical probings. Hallucinations and other anomalous brain experiences, Sacks suggests, lie behind psychical and paranormal phenomena, as well as fairy-tale and folklore descriptions of devils, witches, elves and leprechauns (or, more recently, alien encounters).

Sacks' book comes at a time of exciting developments in hallucination science. A key challenge to progress at present is the question of whether all types of hallucination are caused by the same brain mechanism, or by several distinct ones. In Sacks' natural-history terms, are hallucinations a single species of symptom or a family of species? It seems probable that the answer is a mixture of the two. Although they are

\section{A KEY CHALLENGE IS WHETHER ALL TYPES OF HALLUCINATION ARE CAUSED BY THE SAME BRAIN MECHANISM.}

faulty efference signals. These signals come from the motor system and spread throughout the brain to inform it of impending movement or action. In current psychiatric accounts of hallucinations, faulty efference signals are thought to cause a failure to recognize thoughts, actions or inner speech as originating with oneself, so that they are perceived as spoken or controlled by others.

Other hallucination theories are based on knowledge stored in the brain that influences what we perceive through expectation or preoccupation. Sacks tells us of Marion, for example, who while grieving the loss of her husband, heard and saw him greeting her as she returned home - a 'top-down' influence that might be considered a third species of hallucination.

Current research is seeking to establish whether these apparently different species can be reconciled in a single overarching mechanism. Whatever the outcome, future classificatory schemes of hallucinations and related phenomena are likely to be very different from those we have now.

Hallucinations also take us to the edge of our understanding of perceptual consciousness by hinting at brain functions and processes that we did not even know were there. There is nothing in our models of object vision that explains Rosalie's descriptions, in Hallucinations, of silent multitudes in elaborate Eastern dress, or Marlon seeing his home, in real-

ity ordered and tidy, as a world of chaotic dilapidation. It

very different, hallucinations originating in eye disease, hearing loss, amputation, sensory deprivation or stroke might be considered a single species because, for each, loss of input to the brain triggers a sequence of neurophysiological changes that results in spontaneous neural firing and hallucinations.

Another cause of hallucinations, which might be considered a second species, is is observations such as these, derived from the consulting room, that challenge the neuroscience of perception - and Sacks is leading the way.

Dominic ffytche is Clinical Senior Lecturer in Old Age Psychiatry at King's College London. He specializes in visual hallucinations and related visual perceptual disorders.

e-mail:dominic.ffytche@kcl.ac.uk

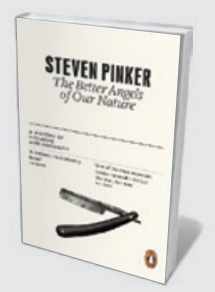

The Better Angels of Our Nature: Why Violence Has Decreased Steven Pinker (Penguin, 2012; \$20)

We are becoming less violent thanks to societal evolution, avers psychologist Steven Pinker, citing significant evidence showing that warfare and murder rates are falling. (See Martin Daly's review: Nature 478, 453-454; 2011.)

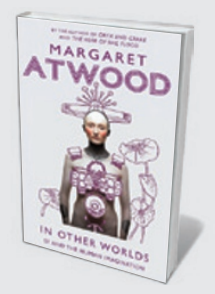

In Other Worlds: SF and the Human Imagination Margaret Atwood (Virago, 2012; £9.99) The creator of dystopian worlds in Oryx and Crake and The Year of the Flood looks to her own work and that of authors such as Kazuo Ishiguro and H. G. Wells in a collection of essays exploring science fiction. (See Q\&A: Nature 478, 35; 2011.) 


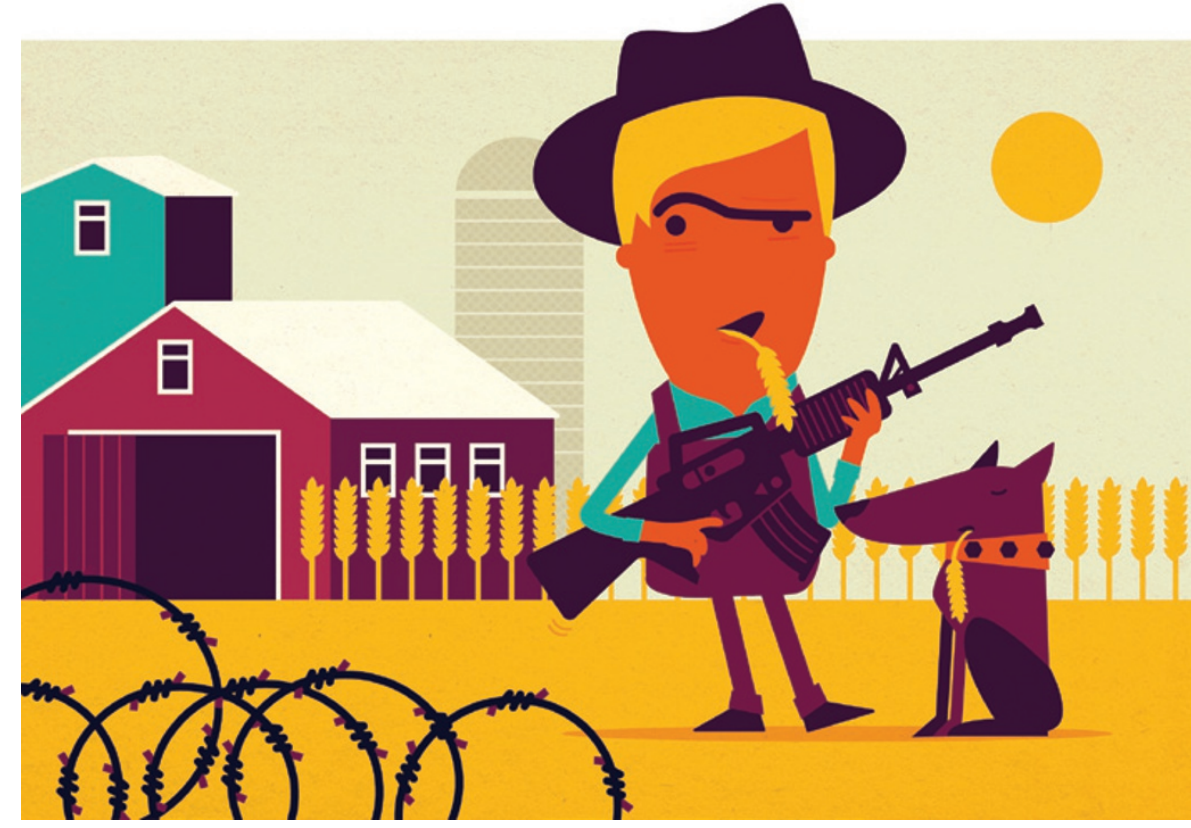

FOOD SECURITY

Growing trouble

\section{Calestous Juma assesses a call for policy to feed the world at a time of squeezed production and soaring prices.}

$\mathrm{W}$ e forget that part of the impetus behind the Arab Spring was the food price spikes of 2007-8. As, globally, we continue to deal with the political and diplomatic ramifications of that, another price spike is projected - this time as a result of serious recent drought in the United States, Latin America and South Asia.

These events are key to assessing the policy relevance of environmental analyst Lester Brown's Full Planet, Empty Plates. Brown's message is that the deteriorating world food situation has far-reaching geopolitical ramifications that demand urgent policy action. Saving civilization, says Brown, needs to be a contact sport, "not a spectator sport".

The book offers some general indication of how that saving might happen - not least through galvanizing the international community. And it stresses the global and systematic nature of the challenges. But the book is silent on the urgent need for an institutional response that matches the magnitude of the problem.

Brown argues that the biggest threat to global stability is the potential for food crises in developing countries. That risk is exacerbated by population growth:

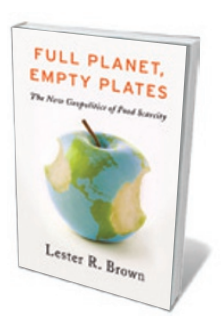

Full Planet, Empty Plates: The New Geopolitics of Food Scarcity

LESTER BROWN

W. W. Norton: 2012

160 pp. \$27.95, £20 some 219,000 peo-

ple are joining the dinner table every night. Meanwhile, the rise in affluence is driving up demand for grain-intensive livestock and poultry products - at a time when nearly one-third of US grain output is being diverted from food to fuel for cars. These challenges are compounded by degradation of farmlands, water scarcity, climate change and the fact that grain yields are starting to plateau.

According to Brown, the overall effect of these dynamics is a dangerous transition from a time of plenty to one of food scarcity. The result is a global rush for land, and "a new geopolitics of food". Brown avers: "Food is the new oil. Land is the new gold." Yet the newness of this thesis is overstated: food has always been a geopolitical issue. The green revolution of the 1960s and 1970s, for example, was inspired by geopolitical considerations; one being the possibility of popular uprisings following famines in countries such as India and Mexico, as was well documented by John Perkins in Geopolitics and the Green Revolution (Oxford University Press, 1997).

How does Brown envisage tackling the dilemmas? He asserts that conventional supply-oriented policy measures such as offering farmers financial incentives and higher price support are simply not enough. Measures of demand form the centrepiece of the book's policy response. They include stabilizing the global population, eradicating poverty, reducing meat consumption and changing biofuels policies by curtailing the growth of the industry and switching to electric vehicles.

On the face of it, Brown's proposals seem sensible. However, the book focuses on what needs to be done, but provides very little indication of how such policies might be implemented. As a result, there are few new insights on how the world can avert the "food breakdown". Although poverty eradication is a desirable goal, so far it has remained elusive, and there are no new ideas here on tackling it.

Probably the weakest aspect of Full Planet, Empty Plates is its failure to clearly outline the institutional mechanisms through which to address the challenge. So far, the world has tried to deal with the issue largely through international bodies such as the United Nations. Their efficacy is now in question, but there is no discussion of alternatives. And the solutions Brown cites derive from national efforts. What works for one country may not work for all.

For example, he alludes to efforts by organizations including the World Bank and the United Nations Food and Agriculture

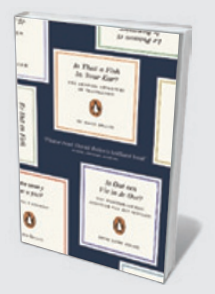

Is That a Fish in Your Ear? The Amazing Adventure of Translation David Bellos (Particular Books, 2012; £8.99) Culture, nationalism and semantics all feature as translator David Bellos gives both a history of the shifting meaning of translation and practical insight into the complexity it involves. (See Ellen Bialystok's review: Nature 477, 536; 2011.)

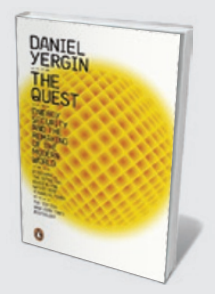

The Quest: Energy, Security, and the Remaking of the Modern World

Daniel Yergin (Penguin, 2012; \$20)

Oil pools at the centre of Daniel Yergin's analysis of the challenge to supply the world with energy. Also focal is his belief that the energy question should be integral to foreign policy. (See Vaclav Smil's review: Nature 477, 403; 2011.) 
- Organization to work out principles for governing land acquisitions in developing countries. This has emerged as one of the most controversial aspects of African agriculture, with most of the land deals concentrated in countries such as Ethiopia, Ghana, Liberia, Madagascar, Mozambique, South Sudan and Zambia.

These are relatively poor countries that need enhanced capability in resource management. Simply offering new guidelines won't do it. Ethiopia, for example, has a long-term vision to modernize its agriculture, but Brown offers little indication of how such countries could play a part.

There have been previous predictions of food crises. A variety of creative responses - especially those made possible by advances in science and technology - helped to forestall disaster and buy the international community time. The green revolution, by introducing inputs such as fertilizer and high-yielding crop varieties, boosted food production. Brown ignores technology, however, even though almost all of the measures he proposes - from the management of population to the expansion of prosperity and switching of energy sources - require the marshalling of human ingenuity.

The green revolution offers another important insight: Latin America and Asia responded to the food crises by expanding local food-production capacity. A global network of agricultural research institutes was created under the Consultative Group on International Agricultural Research (CGIAR) to promote such capacity. The CGIAR is probably the most important geopolitical innovation ever created in response to food crises. The world will need to either strengthen it or offer an alternative.

Full Planet, Empty Plates is a call to arms against the wolf at the door. Admitting the presence of a wolf is one thing; designing an attack strategy is another. For that, we need to turn elsewhere.

Calestous Juma is professor of the practice of international development at Harvard Kennedy School, Cambridge, Massachusetts, USA.

e-mail: calestous_juma@harvard.edu

Random harvest

\author{
Ian Wilmut assesses a critique of how genomics, \\ bioethics and neuroscience are meeting their potential.
}

$\mathrm{T}$ he subtitle of this book - Bioscience's Promethean Promises - led me to expect I would be reading about the harm caused by biomedical research. Instead, I found a scathing account of the failure of recent projects in biology to provide significant new knowledge.

In Genes, Cells and Brains, their fifth book together, sociologist Hilary Rose and her husband, neuroscientist Steven Rose, consider in detail several disciplines that have become fashionable during the past 30 years. These include genomics, experiments on animals, biobanks, regenerative medicine and neuroscience. The duo also reviews mechanisms of evolution and informatics.

The authors introduce each theme with a historical account of its scientific, ethical and sociological background, according to their views. Anyone who has read Love, Power and Knowledge: Towards a Feminist Transformation of the Sciences (Polity, 1994) by Hilary Rose and Alas Poor Darwin: Arguments Against Evolutionary Psychology (Jonathan Cape, 2000), edited by both authors, will know broadly what to expect from their socialist and feminist perspectives. So there is criticism of modern academics being encouraged to patent their research or becoming involved in commercializing their work, and of pre-implantation genetic diagnosis. Whether or not you agree with the Roses' perspectives, they provide thoughtprovoking and interesting contrasts to the secular, neo-liberal view that predominates at present.

The authors describe why, in many cases, they believe that misunderstandings about the underlying biology inevitably led to projects failing to achieve their aims. In their view, for example, the gene-centric view of biology exaggerates the probability of finding linkages between genes and

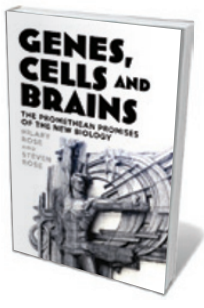

Genes, Cells and Brains: Bioscience's Promethean Promises

HILARY ROSE AND STEVEN ROSE Verso: 2012. $336 \mathrm{pp}$. $£ 20, \$ 26.95$

at the genome-wide association studies of human inherited disease that have sprung up since the human genome was first sequenced. In such studies, the genomes of populations in a community are analysed in a search for evidence that a specific form of a gene (allele) is associated with a high risk of the person having a serious illness. So far, these projects have failed to fulfil the unrealistic expectations that were raised by publicity from the research community.

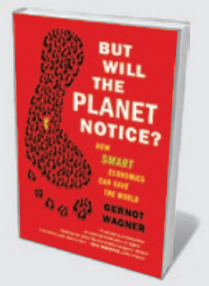

But Will the Planet Notice? How Smart Economics Can Save the World Gernot Wagner (Hill and Wang, 2012; \$16) You can avoid meat, plastic bags and air miles, writes economist Gernot Wagner, but individual choices have no effect on the planet. Harnessing market forces to incentivize green behaviour is the key to confronting climate chaos, he argues.

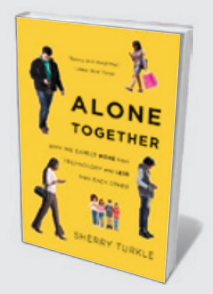

Alone Together: Why We Expect More from Technology and Less from Each Other Sherry Turkle (Basic Books, 2012; \$16.99) Computers are changing the way we interact, warns social scientist Sherry Turkle, leading us to view digital connections as a substitute for intimacy. Many people are 'always online'; others have never known life without computers. 
